\title{
Engineering Libraries: Their Purpose and Organization
}

A TRUE evaluation of engineering libraries cannot be made without first considering the place of engineering in the modern world. To do this involves consideration of the branches of engineering, their functional breakdown and their relation to the basic sciences. The organization of an engineering library then logically must follow the organization of engineering into its various branches and functions.

Engineering is the professional and systematic application of science to the efficient utilization of natural resources to produce wealth. ${ }^{1}$ Engineering, being not a science but rather an application of science, not only depends for its sustenance upon the basic laws of science, primarily those of physics, mathematics, and chemistry, but also finds itself in a highly competitive world intimately related to our economic life.

Herein lies one of the major differences between science and engineering. Engineering except in special cases, such as government work, must produce a profit. Although the fundamental laws on which all work is based are constant, modern design must always reflect an improvement over existing thoughts or equipment. The fact that engineering is so closely dependent upon our economic structure and that its motive is so predominantly for profit, greatly affects publications in the fields of engineering literature.

The conventional branches of engineering are probably best exemplified by the

\footnotetext{
I Hoover, Theodore J. The Engineering Profession. London, Oxford University Press, I94I, p. Io.
}

departments existing in our large technical institutions which, teaching as they do the fundamentals of engineering, must carefully weigh the subject matter of their different technical fields. These fields are civil, mechanical, electrical, chemical, metallurgical, aeronautical, and such miscellaneous fields as naval architecture, fire protection, and safety.

In these engineering fields, each of which has become highly specialized, there are continually new developments which affect their literature. Civil engineering, the oldest branch, has progressed from the remarkable but essentially simple achievements such as the Sphinx and the Coliseum which utilized primarily simple relationships in geometry and statics, to the present highly mathematical plane which provides us today with structures such as the Empire State Building and Boulder Dam. The civil engineer today is no longer only a constructor but is an administrator as well. This modern civil engineering depends upon and is integrated with a host of new fields and techniques such as soil mechanics, welding, reinforced concrete structure, water, and sewage treatment.

Electrical engineering, developed within the past 100 years and having its conception in a very few empirical discoveries, is that branch of engineering which has used to the fullest extent the science of mathematics. The earliest developments consisted of experimental and theoretical design of equipment such as motors, generators, transmission lines, and circuit breakers. 
The discovery of the vacuum tube tremendously expanded the field. Intensive economic competition and, more recently, military requirements, have broadened electrical engineering into the fields of ultrahigh frequency, with radar as the main development and dielectric heating, industrial electronics all appearing and playing a part in electrical technology in the past ten years.

In addition to vertical organization by branches of engineering, there is also a useful and far-reaching subdivision by function. In each branch of engineering, there exists the general main divisions of professional research and development, sales, administration, and instruction. Engineering colleges only recently have taken cognizance of this functional breakdown. In many technological schools in addition to a fundamental four-year program, in mechanical engineering for example, a student now may elect certain options which best fit him for one of the above functional types of engineering.

In research and development, engineering most closely resembles its parent sciences by adapting the laws and resources of nature to utilitarian purposes. Workers in this field are interested in source material on basic fundamentals. Patent literature is one important source of information for this group.

The professional engineer as such forms the largest percentage in the number of practicing engineers, and is the backbone of engineering. The sales engineer is interested in accounting, human relations, business policy, economics, and management, and requires still different material for his special interests.

\section{Engineers and Libraries}

Engineering differs in no way from other professions in depending upon the printed word for most of its learning, and engineers, like scholars, generally turn to libraries in order to extend their knowledge beyond their immediate experience. This is true in all the functions of engineering as well as in the branches and it is the purpose of the library to provide immediate access to published material with little delay and at moderate cost.

The teaching function of the library, which is now becoming more generally recognized, has on the whole been badly neglected in the past. Few engineering libraries offer more than a general lecture or, at the most, a series of lectures to entering freshmen. It is the unusual librarian who has been able to gain the support of his administration to conduct even one course in teaching the use of the library and its resources although the difficulty in using this specialized material may be acknowledged. It would be more effective if engineering school libraries were administered for active cooperation in the educational plan they serve, with a definite place in the engineering curriculum. Pressure from business concerns, aware of the graduates' inability to collect and locate wanted information for reports and investigations, is having some effect, and with more pressure from better-trained and equipped librarians to offer or require such courses, some provision may be more generally developed in the future.

The salient role of the engineering library is not only to prevent duplication of effort and to avoid waste of time, money, and energy on the part of those engaged in original investigations in technology but also to furnish the material needed by those practicing the functions of any of the branches of engineering. This information includes not only the background literature and the basic underlying principles but fully as important, the latest developments 
as well. Adequate use of library facilities would do much to overcome two serious errors frequently made by scientists and technologists, duplication of work already described completely and the failure to appreciate investigations described almost verbatim in the literature. Too often there has been the failure to uncover many investigations published in rather obscure form because of incomplete or inadequate searching of the literature. The library also furnishes the means of locating the information if it is to be found in print elsewhere than in the immediate collection being used.

\section{Employer Must Approve Publication}

Much of the research done by a private individual is not written for publication. There is no reason for an engineer to rush into print with the latest invention or design except for advertising purposes and then only the final result is discussed and not the method of accomplishing it. Much of the criticism for this lack of publication is not justified. An article written by an employee of any of our big, modern engineering companies, such as DuPont or General Electric must be approved by their engineering, publicity, and legal departments before it can be put into print. The question "who are the writers of engineering publications" may well be expressed in the differences in their type of employment, that is, by universities, public utilities, municipal, or private companies; the employees who are furthest removed from private gain are those who write most freely.

This is one reason why so many new engineering achievements are presented to the world as accomplished facts with no advance publications of new principles involved. This policy holds true in times of peace as well as war. The general public is not aware of the fact that this is so but engineering corporations have long since given up hope of finding information in a library as to what their competitors are doing and planning. Only the engineering librarian realizes intensely that the situation exists when he gets repeated requests for information wherein the inquirer insists that he knows that the work is in progress and cannot understand why it is not available in print in the library.

Engineering libraries may be of various types but all are primarily departmental in that they serve a highly specialized field of interest. There are independent technological institutions supported by private, state, or federal funds, separate colleges attached to large universities, departments of public libraries and also private corporations and businesses all of which maintain libraries of this specialized character. These libraries offer a wide range in size and purpose, from such as John Crerar in Chicago, Massachusetts Institute of Technology in Cambridge, and the Engineering Societies' Library in New York whose collections contain hundreds of thousands of volumes and are administered by large welltrained professional staffs, to collections of a few handbooks, texts, and current issues of professional publications for quick reference use in the office of a practicing engineer or professor and cared for by a secretary.

\section{Engineering Literature Important}

Little attention has been given to the library needs of the engineer in the past and provision for engineers in even the largest universities and public libraries has been below the level maintained for other departments. In fact, the development of engineering libraries as such has been a phenomenon almost entirely of the twentieth century. However, as engineering has become more of a science and less of an art, its literature has also become more important. Scientific literature today has at- 
tained great proportions and its volume increases at a faster rate than it can be readily digested and efficiently utilized. This has resulted in a recognition of the fact that only through libraries can the adequate record of engineering progress be kept and engineers keep in complete touch with professional developments. Since the proper use of a technical library presupposes a knowledge of its facilities, familiarity with library research procedures, and an appreciation of the scope and character of the literature of each subject field, it is unfortunate that the average user of library facilities when left to his own resources has little conception of how to use the library aids which are at his disposal.

In a survey sponsored by the Carnegie Corporation, ${ }^{2}$ the libraries of thirty technological institutes of various types were found to be on the whole neglected, having unsatisfactory quarters (few have separate buildings as such), crowded shelves, and insufficient space for readers and staff. The budgets for books and periodicals were small, and with staffs much too limited to handle adequately the heavy burden of routine work with a resultant confusion in the records due to a lack of trained supervision and adequate central control. In many cases departmentalism in similar libraries attached to the larger universities has been pushed so far that there is no central library worthy of the name. Librarians of technological institutions are generally above the average in ability and alertness and certainly are hard working. Even larger and stronger institutions usually have small budgets for the purchase of books and periodicals and a comparison of expenditures shows that liberal arts colleges spent I.97 per cent of their total institutional expenditures for the purchase of books and periodi-

2 Barcus, Thomas R. "The Carnegie Study of the
Libraries of Technological Colleges." Journal of Engineering Education, v. 32, 1942, p. 424-33. cals, universities I.4 per cent, teachers colleges I.34 per cent, and technological colleges .785 per cent. $^{3}$ Another recent survey of eighteen engineering school libraries in the middle Atlantic states ${ }^{4}$ shows a similar percentage for library expenditures with evidence that as a rule, books and periodicals rather than salaries received the bulk of these limited budgets.

\section{Periodical Sources Important}

Standard textbooks and important periodicals are the basic sources of any collection in providing a complete, sure and upto-date source of knowledge of the status of engineering and related science. However, engineering libraries find that while books form the background of what has been acomplished, since they present in permanent form generally accepted theories and facts which often have appeared in periodical publications at an earlier date, in the fields of active development such as science and technology, periodicals which provide the most important sources of current information, have pushed the book into the background. The result is that the strength of such a library is more effectively measured by its periodical content than by the size of its book collection, and the kind and number of current subscriptions to current periodicals is of more importance than the inclusion of complete sets of only a few titles.

Books in a technical library have become of secondary interest, not only because of the time elements necessary for writing, publishing, and distributing they necessarily lag behind current knowledge, but also because with the exception of a comparatively few classics, their use is chiefly for instruction and for quick reference. In

${ }^{3}$ A.L.A. Bulletin February 1941, p. 97.

4 O'Farrell, John B. "The Mechanical Engineering Library Collection; A Survey and Appraisal," (Unpublished paper given at A.L.A. Midwinter meeting. Chicago, December 1946.) 
the past, books in engineering fields have been little more than texts of a limited appeal providing elementary fundamentals and description. Few engineering books are read through from beginning to end and they are used chiefly as sources of information on specific subjects. For this reason most technical books are equipped with well-worked-out indexes, and it logically follows that to make the most effective use of these books it is necessary to provide not only more, but more specific subject entries in the card catalog to make their contents readily available.

Recently a new and better tendency in technical writing and publishing has developed as the profession as a whole has become aware that its activities rest upon scientific foundations and depend upon related fields for their development, and the improvement and durability of engineering literature is the result.

We constantly hear that our scientific and technical books lose their value more quickly than the average publications and certainly the need is almost always for the latest material, the older material being not only out-of-date but often is technically wrong. Obsolescence in technical material is therefore very high, and five years of useful life is probably a fair estimate of the value of the average book. New editions of a title are also more prevalent and the eight editions of Johnson's Materials of Construction in forty-two years (18981939) is not an exception.

\section{Aids to Check Buying}

Quality rather than quantity would seem to be the best plan for the development of the collections in these libraries attempting to secure the best and latest books and periodicals. Since "best" and "largest" are not synonymous, the goal might well be to have every item needed for the purpose of the specific collection and not a single item which cannot be justified by use. New technical and scientific books are usually bought immediately upon the publishers' announcements without a critical examination as to whether or not the material adds to information already available or whether the book is adequate and reliable in its information rather than waiting for the regular reviews which so often appear only months later. Thus the usual book selection aids, such as Publishers' Weekly, Cumulative Book Index, Technical Book Reviews, New Technical Books, Bibliography of Scientific and Industrial Reports become checks rather than guides for buying. Such technical journals as Science and Mechanical Engineering carry information about new books in some form or other, but very few of them have any consistent or adequate program for providing this important information and complete bibliographical information is often lacking. The annual output of new American technical books varies between 300 and 500 new titles, with over 100 new or revised editions.

For these two reasons, the high obsolescence rate and the means used for selection, discarding from the collection becomes as important as acquiring in order to maintain not only adequate but useful book collections. There is not only the problem of providing the latest material but also that of keeping only the correct information since this literature is chiefly factual and descriptive rather than critical.

The staffs of these engineering libraries have almost always been well under the average to be found in other libraries in size, training, and salaries. This is due not only to lack of interest on the part of administrators and faculty but also to the fact that the professional engineer has never been attracted by the lower salaries offered to librarians. Only three librarians of 
the 134 accredited engineering schools are known to have engineering degrees, and many do not have library degrees. This condition is believed to be even more prevalent in the library staffs maintained by private industries. It has generally been felt by the administrators that it is more satisfactory to teach a librarian the needs of the engineers than to attempt to teach an engineer how to operate a library. With the recent promotion of engineering libraries and the development of research, the staff personnel has been improved and increased generally although much remains to be done. Older, more inbred institutions are slower and more reluctant to change and to admit the need of providing better libraries but with more and newer appointments being made from graduates of other institutions, even these institutions are feeling the need to develop their libraries in order to provide their faculties with facilities for continued research and study and the students with the material for preparation in writing reports and reading outside of textbooks.

\section{Organized Societies}

Much has been done in the past five years to improve not only the status of these libraries but their collections, service, and staffs as well. In 1940 engineering school librarians organized sections within the American Library Association and the American Society for Engineering Education to promote not only a better recognition of their purposes and needs but also to the necessity of supplying this library service to engineers. The American Library Association group had the special purpose :

to strive to promote library service and librarianship in engineering schools, encourage mutual cooperation with other organizations in the field of engineering education, and carry out a program of activities designed to advance the standards of library service in engineering schools. ${ }^{5}$

The section of the American Society for Engineering Education aims more toward a better coordination of the library within the curriculum, the development of the teaching function of the library by more or less formal instruction in the use of the library facilities, and the promotion of the librarian as a faculty member. A similar group within the Special Libraries Association constitutes the largest section numerically but its membership has more of an industrial background and is interested in the exchange of ideas and materials and techniques rather than the broader principles of development.

5 "Constitution, Engineering School Libraries Section," Association of College and Reference Libraries.

\section{Progress Report of the Junior College Section, A.C.R.L.}

Edited by Mary Harrison Clay, section chairman, a mimeographed "Progress Report" of the Junior College Section of A.C.R.L. was issued last August. In addition to a statement by Miss Clay concerning the year's activities and future prospects for development, there are also reports from the various regional chairmen: New England, by Kathryn E. Parke; Pacific Northwest, by Helen Ruth Montague; California, by Elizabeth Neal; North Central States, by Alice Elizabeth Golden; Middle States, sent through Dorothy Hill Staples; and Southern Association, by Lola Rivers Thompson.

The report as a whole reveals the great variety of problems in the junior college libraries of the country. The report should be of much value to junior college librarians as well as to the future officers of the junior college section. 